\title{
Paediatric surgical conditions in Malawi - A cross- sectional nationwide household survey
}

\author{
Carlos Varela ${ }^{1,2,3}$, Asgaut Viste ${ }^{5}$, Sven Young ${ }^{1,2,4}$, Reinou S. Groen $^{6,7}$, Leonard Banza ${ }^{1,2,3}$, Bip Nandi ${ }^{1,8}$, \\ Nyengo Mkandawire', Bente Elisabeth Moen ${ }^{3}$
}

1. Department of Surgery Kamuzu Central Hospital, Lilongwe, Malawi

2. Department of Surgery, University of Malawi, College of Medicine, Lilongwe, Malawi/Kamuzu University of Health Sciences

3. Centre for International Health, Department of Global Public Health and Primary Care, University of Bergen, Bergen, Norway

4. Department of Orthopaedic Surgery, Haukeland University Hospital, Bergen, Norway

5. Department of Research and Development, Haukeland University Hospital, Bergen, Norway

6. Department of Obstetrics and Gynecology, Johns Hopkins Medicine, Baltimore, USA

7. Department of Obstetrics and Gynecology, Alaska Native Medical Centre, Anchorage, USA

8. Michael E. DeBakey Department of Surgery, Baylor College of Medicine, Houston, USA

9. Department of Surgery, University of Malawi, College of Medicine, Blantyre, Malawi/Kamuzu University of Health Sciences

Correspondence: Carlos Varela, (cegomesv@gmail.com)

\section{Background}

Untreated surgical conditions may lead to lifelong disability in children. Treating children with surgical conditions may reduce longterm effects of morbidity and disability. Unfortunately, low- and middle-income countries have limited resources for paediatric surgical care. Malawi, for example, has very few paediatric surgeons. There are also significantly inadequate infrastructures and personnel to treat these children. In order to strengthen resources that could provide such services, we need to begin by quantifying the need.

Aim

To estimate the approximate prevalence of surgical conditions among children in Malawi, to describe the anatomical locations and diagnoses of the conditions and the presence of injuries.

Methods

A cross-sectional, nationwide survey of surgical needs was performed in 28 of 29 districts of Malawi. Villages, households and household members were randomly selected. A total of 1487 households were visited and 2960 persons were interviewed. This paper is a sub analysis of the children in the dataset. Information was obtained from 255 living children and inquiry from household respondents for the 255 children who had died in the past year. The interviews were conducted by medical students over a 60 -day period, and the validated SOSAS tool was used for data collection.

Results

There were 67 out of $255(26.3 \%)$ total children living with a surgical condition at the time of the study, with most of the conditions located in the extremities. Half of the children lived with problems due to injuries. Traffic accidents were the most common cause. Two-thirds of the children living with a surgical condition had some kind of disability, and one-third of them were grossly disabled. There were 255 total deceased children, with 34 who died from a surgical condition. The most prevalent causes of death were congenital anomalies of the abdomen, groin and genital region.

Conclusion

An extrapolation of the $26 \%$ of children found to be living with a surgical condition indicates that there could be 2 million children living with a condition that needs surgical consultation or treatment in Malawi. Congenital anomalies cause significant numbers of deaths among Malawian children. Children living with surgical conditions had disorders in their extremities, causing severe disability. Many of these disorders could have been corrected by surgical care.

Key words; Prevalence, Surgical conditions, Children, Malawi, SOSAS

\section{Introduction}

Untreated surgical conditions in children may result in lifelong disability or death. In low- and middle-income countries (LMICs), there is a high burden of unmet surgical need in the paediatric population. A data analysis of numbers from four LMICs (Uganda, Sierra Leone, Rwanda and Nepal) using a validated Surgeons Overseas Assessment of Surgical Need (SOSAS) tool, showed that $19 \%$ of the children (0-18 years) had a surgical need and $62 \%$ of those children had one unmet surgical need ${ }^{1}$. The SOSAS tool was developed for population-based household surveys to assess surgical needs in LMICs.
There is a great need for improved access to surgery globally. LMICs, especially in sub-Saharan Africa (SSA), are the countries with the most limited access to health care resources $^{2,3}$. This region has a disproportionate unmet need for surgical care compared with other parts of the world. An estimate by the Disease Control Priorities Project, which determines priorities for disease control around the world ${ }^{4}$, stated that $11 \%$ of the total burden of disease in LMICs was from surgically correctable conditions ${ }^{5,6}$. The treatment and care for children who have a surgical condition is underappreciated and inadequately funded in this region ${ }^{7,8}$. A study carried out in Gambia showed that most surgical deaths in children were from burns, congenital anomalies 
and injuries?. There are very few paediatric surgeons in the SSA region as a whole. A study on the unmet need of paediatric surgery demonstrates this deficit ${ }^{10}$. In SSA, The number of regional surgeons per 100,000 people is 0.5 as compared to the USA where the number is $54.7 / 100,000^{10}$. Most countries in SSA have few paediatric surgery providers, including nurses, anaesthetists and surgeons. East and Central African countries such as Mozambique, Tanzania, Zambia, Zimbabwe and Malawi have between 3 and 8 paediatric surgeons nationwide. There is a need to train, employ and retain paediatric surgical teams ${ }^{10}$.

Surgical teams in SSA are not only dealing with very poor socio-economic conditions and an overwhelming burden of disease, but also rare and advanced pathologies, which they must address without having much subspecialisation. In this region, infrastructure and the health care workforce are underdeveloped and fail to address the unmet paediatric surgery needs in this region ${ }^{8}$. A study on funding for paediatric surgery showed that paediatric operations are seldom performed in $\mathrm{SSA}^{11}$ because of inadequate finances and the necessary out-of-pocket payments by a patient's family. There is also limited access to critical paediatric surgical procedures.

The literature on neonatal and paediatric surgery in SSA is limited. There are significant gaps in children's surgical care and strategies for children's surgery are absent from the national health plans. The National Health Strategic Plans for 47 independent countries do not have any sections on surgery for children ${ }^{12}$, despite the fact that congenital anomalies are common surgical conditions in children and that these carry a high risk of neonatal death, life-long risk of disability and disproportionately increase the number of disability-adjusted life years (DALYs) $\operatorname{lost}^{13}$.

In Uganda it is estimated that $55 \%$ of the country's surgical needs are attributed to the paediatric population. To address this, improved training of specialists in paediatric surgical care is required ${ }^{14}$. In Zambia a large proportion of the population does not have access to safe and timely surgical care owing to limited resources in hospitals providing surgical care ${ }^{11}$. In Somaliland there is a $12.2 \%$ prevalence of paediatric surgical conditions among all children. Only $23.7 \%$ of these had been surgically treated at the time of the survey ${ }^{15}$.

\section{Study significance}

Our previous study in Malawi showed that the prevalence of untreated surgical conditions in the general population is $35 \%{ }^{16}$. Just as in many other SSA countries, surgical care is a low health care priority in Malawi. Another study showed that paediatric surgical patients represented $18 \%$ of all surgical admissions at a referral hospital ${ }^{17}$. Also, $9.7 \%$ of all paediatric admissions at a central hospital in Malawi were related to accidents, burns and fractures from falls ${ }^{3}$. Malawi has only six paediatric surgeons working in the referral centres that offer paediatric surgery services ${ }^{10,18}$. This clearly demonstrates the inadequacy of paediatric surgery services in Malawi at a national level.

The World Health Assembly resolution WHA 68.15 ${ }^{19}$ recognises the importance of strengthening emergency and essential surgical care as a component of universal health care. Therefore, to plan for universal care strategies in
Malawi, it is necessary to quantify and describe untreated paediatric surgical conditions among Malawian children at a national level. This information can be used to inform human resources and infrastructure planning for paediatric surgical services in Malawi. This study aimed to estimate the approximate prevalence of surgical conditions among children in Malawi, to describe the anatomical locations and diagnoses of the conditions and the presence of injuries. A secondary aim of the study was to describe the children's experiences when accessing surgical health care and the disability level of the children.

\section{Materials and methods}

This data is a part of a national population-based, clusterrandomised household survey of the prevalence of surgical conditions within the general population in Malawi. The detailed methodology has been previously described ${ }^{16,20,21}$ and is summarised below. This analysis is focused on a subset of the data describing surgical conditions among children in Malawi.

\section{Setting}

Malawi is in Southern Africa and has a population of 18.4 million people ${ }^{22-24}$. The Gross National Income (GNI) per capita is $\$ 340$ per annum (World Bank group, 2016) 23. There $^{23}$ are 9.8 million (51.6\%) people below the age of 18 years in Malawi ${ }^{24}$. The country is divided into three geographic regions, and has 28 administrative districts. There are about 48,000 registered settlements, and the majority of people live in rural areas. Within the total population, 0.5 million people $(3 \%)$ are infants under the age of 1 year, 2.6 million people $(15 \%)$ under the age of 5 years, and 6.7 million people $(37.2 \%)$ are aged between 5 and 17 years ${ }^{23,24}$ (Table 1).

\section{Sampling and data collection}

The original prevalence study carried out in $2017^{16}$, undertaken to identify adult surgical needs, utilised 1487 households, and 2960 individuals were interviewed. Sample size was estimated based on the findings of the pilot study, which had estimated the prevalence of untreated surgical conditions to be at $25 \%$, based on the reports from other African countries that had carried out similar studies ${ }^{14,25,26}$. Population and census information was obtained from the Malawi Statistics Office 23, 24. In the general Malawi population, $51.6 \%$ are under the age of 18 years ( $49 \%$ male, $51 \%$ females). In our study, the representation for the age group under the age of 18 years was $50 \%$ (52\% male, $48 \%$ female). These very similar findings in our study population were therefore found to be representative for extrapolation of the findings to the national population. However, extrapolations always have a degree of uncertainty and numbers are therefore presented with $95 \%$ confidence intervals (Table 1).

A list of enumeration sites was provided based on 2008 Malawi population and census data ${ }^{23}$. We randomly selected 55 settlements (villages with houses for different families) from the 28 administrative districts using computer generated random numbers; $2-4$ households were randomly selected from each settlement. Random selection of households was done by spinning a bottle after exiting the initial household, and counting the $3 \mathrm{rd}$, 5th or 7 th house in the direction of the bottle top. 
Table 1.The age distribution of the Malawi population ${ }^{26}$ and the study population by numbers and percent.

\begin{tabular}{|c|c|c|c|c|c|c|}
\hline Age (years) & \multicolumn{3}{|c|}{ Study population $(95 \% \mathrm{Cl})$} & \multicolumn{3}{|c|}{ Malawi population (million) ${ }^{26}$} \\
\hline & M & $\mathrm{F}$ & Total n (\%) & M & $\mathrm{F}$ & Total n (\%) \\
\hline $0-5$ & 175 & 112 & $287(11.7)$ & 1.5 & 1.6 & $3.1(18.0)$ \\
\hline $6-13$ & 329 & 307 & $636(26.0)$ & 2.6 & 2.5 & $5.1(28.3)$ \\
\hline $14-17$ & 135 & 167 & $302(12.3)$ & 0.7 & 0.9 & $1.6(8.9)$ \\
\hline Total $<18$ & 639 & 586 & $1225(50.0)$ & 4.8 & 5.0 & $9.8(51.6)$ \\
\hline$>18$ & 338 & 879 & $1217(49.7)$ & 3.6 & 5.1 & $8.7(48.3)$ \\
\hline Total & 977 & 1465 & 2442 & 8.1 & 9.9 & 18.5 \\
\hline $\begin{array}{c}\text { Missing } \\
\text { data for sex }\end{array}$ & & & 6 & & & \\
\hline Grand total & & & 2448 & & & \\
\hline
\end{tabular}

Table 2. Children with a surgical condition by age.

\begin{tabular}{|c|c|c|c|c|c|}
\hline \multirow{2}{*}{ Age } & \multicolumn{2}{|c|}{ Living children } & \multicolumn{2}{c|}{$\begin{array}{c}\text { Deceased children } \\
\mathrm{n}(\%)\end{array}$} & \multirow{2}{*}{ Total $\mathrm{n}$} \\
\cline { 2 - 5 } & $\begin{array}{c}\text { Surgical } \\
\text { conditions }\end{array}$ & $\begin{array}{c}\text { Non-surgical } \\
\text { conditions }\end{array}$ & Surgical conditions & $\begin{array}{c}\text { Non-surgical } \\
\text { conditions }\end{array}$ & \\
\hline $0-4$ & $7(2.7)$ & $20(7.8)$ & $22(8.6)$ & $166(65.1)$ & 215 \\
\hline $5-13$ & $31(12.2)$ & $90(35.3)$ & $9(3.5)$ & $43(16.9)$ & 173 \\
\hline $14-17$ & $29(11.4)$ & $78(30.6)$ & $3(1.2)$ & $12(4.7)$ & 122 \\
\hline Total & $67(26.3)$ & $188(73.7)$ & $34(13.3)$ & $221(86.7)$ & 510 \\
\hline $\begin{array}{c}\text { Grand } \\
\text { total }\end{array}$ & \multicolumn{3}{|c|}{255} & \multicolumn{2}{|c|}{255} \\
\hline
\end{tabular}

Table 3. Anatomical location for surgical conditions by age (number of children)

\begin{tabular}{|l|c|c|c|c|}
\hline \multirow{2}{*}{ Location of surgical condition } & \multicolumn{3}{|c|}{ Age } & \multirow{2}{*}{ Total } \\
\cline { 2 - 4 } & $0-4$ & $5-13$ & $14-17$ & \\
\hline Living children & & & & \\
\hline Face, head and neck & 2 & 10 & 8 & 20 \\
\hline $\begin{array}{l}\text { Torso (chest, back, abdomen, groin and } \\
\text { genital) }\end{array}$ & 2 & 5 & 8 & 15 \\
\hline Extremity & 3 & 16 & 13 & 32 \\
\hline Total & 7 & 31 & 29 & 67 \\
\hline & & & & \\
\hline Deceased children & 3 & 1 & - & 4 \\
\hline Face, head and neck & 19 & 8 & 3 & 30 \\
\hline $\begin{array}{l}\text { Torso (chest, back, abdomen, groin and } \\
\text { genital) }\end{array}$ & - & - & - & - \\
\hline Extremity & 22 & 9 & 3 & 34 \\
\hline Total & & & & \\
\hline
\end{tabular}

The number of households depended on village size. Demographic and general family data were collected from the household head. Subsequently another household member was randomly selected for the questionnaire, and included both adults and children. Consent and assent forms were read out to the household members prior to the interview, and those who accepted and gave consent were interviewed. For the youngest age group, below 10 years, the household head present at the moment was responding on their behalf, while the older children responded for themselves.

Data collection was performed by 32 medical students from Malawi College of Medicine who were in their third year of medical training. A pilot study was conducted prior to the main survey at the national level. Data collectors had 5 days' training on usage of the tablet-based data collection tool. All the 28 administrative districts were visited for data collection except for Likoma, which is an island. 
Table 4. Surgical diagnosis by age (number of children).

\begin{tabular}{|l|c|c|c|c|}
\hline \multicolumn{1}{|c|}{ Diagnosis of surgical condition } & \multicolumn{3}{|c|}{ Age } & \multirow{2}{*}{ Total } \\
\cline { 2 - 4 } & $0-4$ & $5-13$ & $14-17$ & \\
\hline Living children & & & & \\
\hline Wound from injuries (burn, fracture) & - & 13 & 12 & 25 \\
\hline Congenital deformity & - & 5 & 6 & 11 \\
\hline $\begin{array}{l}\text { Acquired deformity (non-injury wounds, } \\
\text { mass/growth) }\end{array}$ & 5 & 19 & 7 & 31 \\
\hline Total & 5 & 37 & 25 & 67 \\
\hline & & & & \\
\hline Deceased children & & & & \\
\hline Wound from injuries (burn, fracture) & 2 & 4 & - & 6 \\
\hline Congenital deformity & 11 & 3 & 1 & 15 \\
\hline $\begin{array}{l}\text { Acquired deformity (non-injury wounds, } \\
\text { mass/growth) }\end{array}$ & 9 & 2 & 2 & 13 \\
\hline Total & 22 & 9 & 3 & 34 \\
\hline
\end{tabular}

Table 5. Cause of injury by age (number of children).

\begin{tabular}{|l|c|c|c|c|}
\hline \multicolumn{1}{|c|}{ Mechanism of injury } & \multicolumn{3}{c|}{ Age } & Total \\
\hline & $0-4$ & $5-13$ & $14-17$ & \\
\hline Living children & & & & \\
\hline Traffic accident & - & 3 & 8 & 11 \\
\hline Other injuries (stab/cut, bite, fall, burn) & 1 & 5 & 8 & 14 \\
\hline Total & 1 & 8 & 16 & 25 \\
\hline & & & & \\
\hline Deceased children & & & & \\
\hline Traffic accident & - & 1 & 1 & 2 \\
\hline Other injuries (stab/cut, bite, fall, burn) & 1 & 2 & 1 & 4 \\
\hline Total & 1 & 3 & 2 & 6 \\
\hline
\end{tabular}

The data collection process lasted for 10 weeks and was undertaken from July to August 2016. Interviews were conducted in the local language.

\section{Survey instrument}

Data was collected using a questionnaire. Children between the age of 0 and 18 years were identified as survey respondents. After an initial inquiry of both living and deceased children in the household, a three-component questionnaire was verbally administered by data collectors who input the data on the tablet-based collection tool. The first component of the questionnaire inquired about the general household demographics and household members. It included the number of members, their ages, sex, tribe and occupations. The second and third component focused on the individual information concerning each child. For a living child, the respondent was asked if the child currently had a clinical condition that could be described as a surgical condition. The child or respondent for the child was asked if the child had ever experienced a wound, burn, mass, deformity, problem with eating or drinking, a problem with eyes or ears or an operation. This enquiry was asked for each of the following body regions: head, face and neck, chest/ breast, back, abdomen, groin and genitals, and extremities. They were asked if the problem started after an injury or accident, what kind of accident this might have been and when the problem started. They were also asked if they had the problem currently, and if this problem had an impact on the daily life of the child.

The data collectors also enquired whether there had been any death of a person in the household under the age of 18 years within the prior 12 months and the likely cause of death.

The participants were also asked if the child attended a health care facility or not, and the type of care provided including a surgical procedure or operation. The child or respondent for the child was asked about what kind of treatment they had received. The options were: none, major procedure (with general anaesthesia), or minor procedure (wound care, suturing, incision and drainage, wound care and dressing). They were also asked about the main reason for not to going to a health facility to see a doctor, have an operation or receive wound care and dressing. The tool was translated into the main local language, Chichewa before the interview. During interviews in areas where there were difficulties in understanding Chichewa, a translator was used to maintain the uniformity of the collected data. The translation was undertaken by persons identified for that purpose for each specific region. 
Table 6. Access to formal surgical healthcare by age (number of children).

\begin{tabular}{|c|c|c|c|c|}
\hline \multirow{3}{*}{ Reason for not receiving formal health care } & \multicolumn{3}{|c|}{ Age } & \multirow[t]{3}{*}{ Total } \\
\hline & & & & \\
\hline & $0-4$ & $5-13$ & $14-17$ & \\
\hline \multicolumn{5}{|l|}{ Living children } \\
\hline No money for Health care & - & - & - & - \\
\hline No transport money & - & - & - & - \\
\hline No time to seek health care & - & - & 2 & 2 \\
\hline Fear/lack of trust & - & 2 & 2 & 4 \\
\hline Unavailable facility/personnel & - & 5 & 1 & 6 \\
\hline Received formal surgical health care & 28 & 21 & 6 & 55 \\
\hline Total & 28 & 28 & 11 & 67 \\
\hline \multicolumn{5}{|l|}{ Deceased children } \\
\hline No money for health care & 3 & - & - & 3 \\
\hline No transport money & - & - & - & - \\
\hline No time to seek health care & 4 & 5 & 1 & 10 \\
\hline Fear/lack of trust & 3 & - & 1 & 4 \\
\hline Unavailable facility/personnel & 7 & 3 & 1 & 11 \\
\hline Received formal surgical health care & 4 & 2 & - & 6 \\
\hline Total & 21 & 10 & 3 & 34 \\
\hline
\end{tabular}

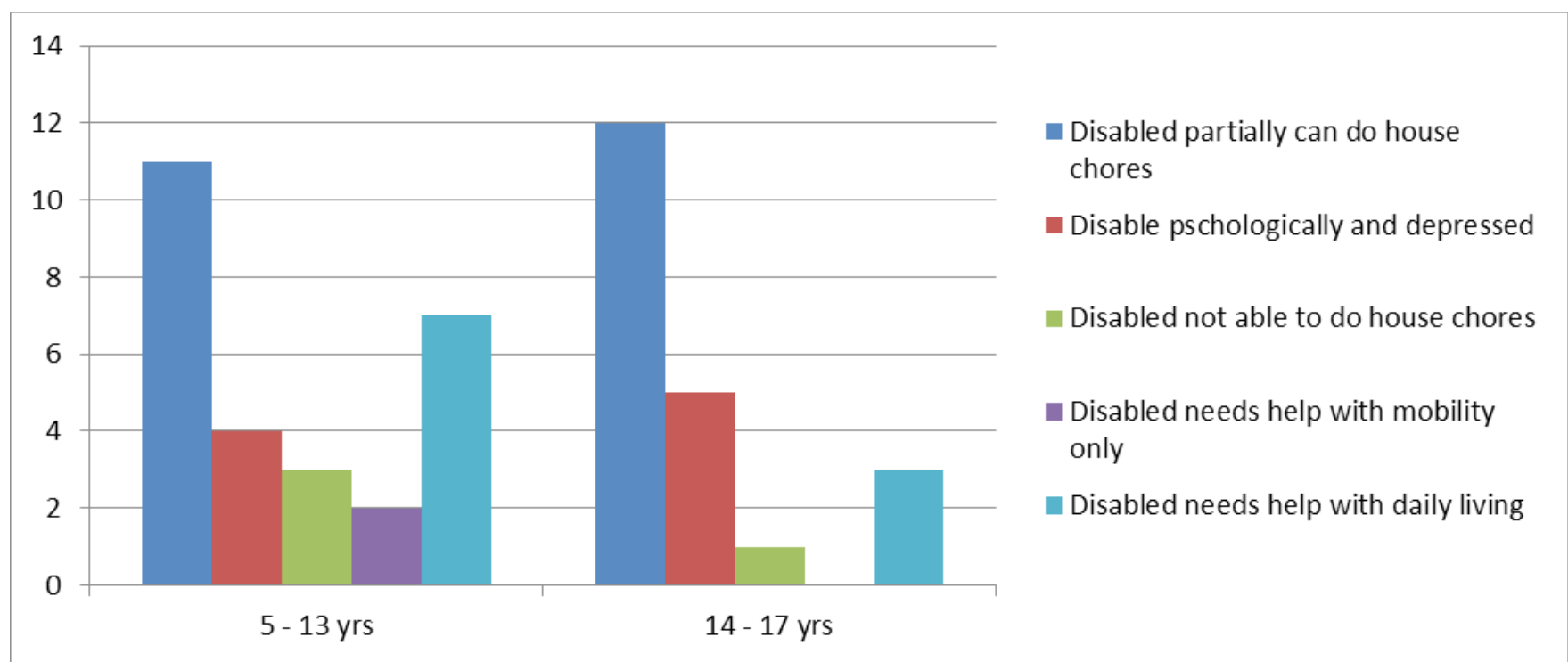

Figure 1: Disability in surgical conditions by age (number of children).

\section{Ethical approval and consent to participate}

The research was approved by the College of Medicine Research Ethics Committee (P03/15/1696), and Norwegian Regional Research ethics committee (2016/1392/REK Vest). Consent (for the adults) and assent (for the children) forms were designed and translated into the local languages. These were read out in a local language to the participants to seek informed consent prior to conducting the interviews. The consent and assent forms were approved by the ethics committees as part of the questionnaire for data collection.

\section{Statistical analysis}

Data were analysed for two categories of children: living children and the children who had died in the previous 12 months prior to the survey (deceased children). Numbers and percentages were given.
Frequencies were reported for age categories.

Pearson chi-square test was used to compare living and deceased children for location of surgical conditions, availability of health facility and health care provider.

Data analysis was done by SPSS version 24 (IBM, New York).

\section{Results}

The total number of children analysed was 510. Of these, 255 were alive at the time of the survey and 67 (26.3\%) of these children had probable surgical conditions. Sixty of these children were 5 years or older. At the time of the survey, 255 children had died in the prior 12 months, and $34(13.3 \%)$ of these children were identified as having died due to a probable surgical condition. Twenty-two of these children were less than 4 years old when they died (Table 2). https://dx.doi.org/10.4314/mmj.v33i2.2 
Of the 67 children living with a suspected surgical condition, the extremities were the most common location, affecting 32 children. Of the 34 children who had died from a suspected surgical condition, the torso (chest, back, abdomen, groin, and genital region was the most common location (Table 3).

Of the living children, acquired deformity and wound from injuries were the most common aetiologies. Seven children had experienced a limb fracture. In the deceased children congenital deformities were the most common, with 15 of 34 children (Table 4).

Injuries contributed to 25 of the 67 children living with surgical conditions. Isolated traffic accidents were the most common mechanism of injury, with almost half (11) of the cases of injured children resulting from road traffic. There rest of the injuries were from different aetiologies, i.e. bite, fall, stab and burn. Six children died from injuries (Table 5).

Of the 67 children living with a surgical condition, 12 did not receive formal health care, due to fear or lack of trust, or no facility available, or having no time to seek health care; for 6 children there were no facility or health care personnel available. Of the 255 deceased children, 28 did not receive health care, and in 11 children there were no available personnel or health facility. A total of $40(39.6 \%)$ of the children with a surgical condition did not receive health care. Of the causes stated by the caregivers of the 34 deceased children, 11 stated they had no access to a health facility and 10 stated to not have the time to seek health care (Table 6).

There were 7 of the 67 children with a surgical condition that had either a major or minor surgical procedure. Four of the deceased children had a major surgical procedure for their condition.

Some type of disability was reported for 48 of the 67 living children above the age of 5 who had a surgical condition. Almost half (23) of these children were able to do normal activities of daily living, such as household chores. A third (16) of the 48 children with a disability were grossly disabled and could not function on their own without assistance with either mobility or their daily living activities and could not do household chores (Figure 1).

\section{Discussion}

This study demonstrates a need for better surgical treatment and care among children in Malawi. About one-fourth of the interviewed children or child respondent had health problems due to a probable surgical condition, mostly from the extremities. Almost half of the children lived with problems due to injuries, and traffic accidents were the common cause. Two-thirds of the children with a surgical condition had some kind of disability, and only half of them were able to perform normal household chores; one-third was grossly disabled. Children who had died from a probable surgical condition had different diagnoses than the living children, mainly congenital deformities located in the abdomen/ groin/genital region. Some of the children had not received any surgical health care, mainly due to unavailability of care of this type, but also caused by lack of time to seek help for the condition.

According to the population estimates; $26 \%$ of living children in our study have a surgically correctable condition.
An extrapolation to the whole population of Malawi shows that out of 9.3 million of the total population under 18 years, there could be almost 2.4 million children living with a surgically correctable condition in Malawi, and over a million children might be disabled.

Due to limited surgical care for children in LMICs, many children miss the opportunity for surgical correction of their condition, and may end up with life-long disability, hampering the economic development of their families and the nation as a whole. In our study we demonstrated that $26.3 \%$ of the living children in our study group have a condition that could possibly be treated by surgery. These findings coincide with those from a similar study that looked at untreated surgical conditions in Malawi ${ }^{16}$. Untreated surgical conditions account for almost $10 \%$ of disabilities among children in Malawi, with $6.7 \%$ of all causes of deaths occurring from an untreated surgical condition among these children. With very few surgical care providers for children at a national level, the health and well-being of these children is at stake. Malawi, like many other LMICs, has a ratio of 1-3 paediatric surgeons per 1-2 million children ${ }^{10,14,27,28}$.

Other African countries have a low density of surgeons, such as Uganda, 0.73/100,000, and Rwanda, 0.49/100,000 ${ }^{10,14}$. This clearly shows the much lower numbers of surgical providers compared with the developed countries, with regional surgeon numbers per 100,000 population of 0.5 in LMICs, compared with 54.7 surgeons per 100,000 population in the USA ${ }^{10}$.

Apart from having an insufficient number of surgical providers, facilities available to offer paediatric surgery are also inadequate in these LMICs. In our study, the information gathered on paediatric surgical care is from 2016. The authors consider this is still representative of the current situation, because there has not been significant development in infrastructure and human resource capacity to care for children's surgical conditions in the district hospitals. In Malawi there are a few facilities that offer paediatric surgery and most are located in large urban centres, limiting access to paediatric surgical care for most of the population. Travel to these centres has many challenges, including difficulties of travel and availability of financial support ${ }^{20}$. We have demonstrated that parents for almost $50 \%$ of the children will seek some formal health care for their children, but that medical facilities and personnel were not available for $4 \%$ of these children. For those that managed to get formal health care, only $10 \%$ of the total children were treated by surgery.

Traumatic injuries also contribute to many of the surgical conditions faced by these children. Our study showed that $31 \%$ of total surgical conditions in children resulted from injury and $42 \%$ of these were due to road traffic accidents. It has previously been shown in Malawi that trauma cases at a referral centre had $36.8 \%$ children under the age of 18 years injured over a 7 -year period, with $20.1 \%$ due to road traffic accidents $^{30}$.

Congenital deformities accounted for $24 \%$ of all surgical conditions for both the living and deceased children. This was $4.7 \%$ of the entire child population in our study, or 340,000 children with congenital anomalies nationwide. Most of these congenital clinical conditions are surgically correctable. 
There are 1125 children born with a club foot in Malawi per year ${ }^{26}$. We noted in our study that the common surgical conditions were mostly in the extremities $(32 \%$ of surgical conditions, $6.2 \%$ of the childhood population). This gives an estimate of 446,400 children with surgical conditions in the limbs. Of these, an estimated 100,000 have these clinical conditions located on the foot, which are most commonly club foot deformities.

Clinical conditions in the groin can be interpreted as mostly inguinal hernias that are surgically correctable, but most individuals do not undergo this surgical repair.

A study on children with disabilities from cerebral malaria in Malawi showed gaps in education, knowledge, rehabilitation infrastructure funding and stigma for caring of the disabled children ${ }^{30}$. We note that surgical conditions also cause much disability to children. In our study $26.5 \%$ of the children over the age of 5 years living with a surgical condition needed to be assisted with daily living activities, including feeding, bathing themselves and also mobility. Physical rehabilitation would probably be a good alternative but assistance for most of these children would not be sought from a health care facility for a variety of reasons. In particular, some would not go to a health care facility because of being unable to source funds for transportation and in some cases no such transportation is available ${ }^{21}$. The health care facilities that may be able to offer rehabilitation services may be located far from the rural areas, rendering transportation difficult. The facilities offering surgery and rehabilitation are usually located in the main cities of Malawi. These centres only provide service to cases referred from the secondary level hospitals (district hospitals). Most of these secondary level hospitals lack paediatric surgical providers and sometimes also the basic equipment for physical rehabilitation and surgical procedures.

The Ministry of Health in Malawi takes responsibility to prevent premature deaths and disability in children (Child Protection and Justice Act 2010). The Ministry of Health also promotes health workers to visit disabled children with child protection risks to offer support, which includes identification, advice and recommendation to visit a health facility $^{31}$. There is, however, also a clear need to improve access to health services for children with disabilities and surgical conditions to avoid inequity in access for this vulnerable group of children ${ }^{32}$.

\section{Study strength}

The size and geographical width of the study had data covering the whole of Malawi. In addition a validated SOSAS tool was used, with trained data collectors who understood the language, culture of the country and the presentations of the children's clinical conditions.

\section{Study limitations}

The SOSAS tool was not designed to capture the exact clinical conditions or doctor-confirmed diagnosis. The surgical diagnosis was based on self-reports from the interviewed persons. Obtaining accurate information on the diagnoses would have required a very different study design. Augmenting the interviews with visual aids or pictorial capture of the clinical conditions might have improved the quality of the diagnoses reported, but still, without a specialist opinion, the diagnoses would not have been certain. Another limitation was recall bias, especially related to the deceased children, as the death could have happened months before the interview. Also, the family member interviewed might have been uncomfortable to discuss such events.

\section{Study implication}

An extrapolation of the $26 \%$ of children who were found to be living with a surgical condition in this study indicates that there could be 2 million children living with a surgical condition in Malawi.

\section{Study recommendation}

With this identified surgical need, it is clear that scaling up paediatric surgery services is necessary in Malawi. Promoting paediatric surgery training in the available training institutions and reinforcing infrastructure for paediatric surgery at all levels of health care service is likely to reduce the burden of untreated surgical conditions and related disabilities among children in Malawi, and the region.

\section{Conclusion}

This study has uncovered that a large group of children are living with disability from a surgical condition in Malawi. Many children may also die unnecessarily from surgical conditions. The most common cause of death was congenital abnormalities of the abdomen/groin and genitals. Among living children, surgical conditions were most often seen in the extremities, rendering most children disabled. Acquired conditions were mostly associated with trauma. Many of these disorders would have benefited from better surgical care.

\section{Funding}

Permission to use the SOSAS tool was granted at no cost by the Surgeons Overseas group. The Norwegian Agency for Development Cooperation (NORAD) financed a "Norhed" Programme supporting the training of surgeons and surgical research in Malawi. This programme provided a $\mathrm{PhD}$ grant to authors $\mathrm{CV}$ and $\mathrm{LB}$, payed the costs for the data collection exercise and financed the computer tablets for data collection. The computer tablets were donated to the Kamuzu Central Hospital Surgery Department for further surgical research at the end of the study. The Norhed programme also covered costs in relation to support for data collectors' meals, transport costs and accommodation during the data collection period.

\section{Competing interests}

None of the authors have any competing interests to declare.

\section{Authors' contributions}

CV: project idea, planning implementation, data collection, first manuscript draft and revisions.

SY: project idea and planning, supervision, data interpretation, manuscript revisions.

NM: supervision, data interpretation, manuscript revisions.

RSG: supervision, data interpretation, manuscript revision.

$\mathrm{BN}$ : Manuscript revisions.

https://dx.doi.org/10.4314/mmj.v33i2.2 
LB: data collection, manuscript revisions.

AV: project idea and planning, supervision, manuscript revisions, assisted with data analysis and interpretation.

BEM: supervision, planning and manuscript revisions.

All the above authors have reviewed and approved the manuscript for submission for publication.

\section{Acknowledgements}

The authors would like to thank the data collectors (third year medical students class of 2016 at Malawi College of Medicine): Manduwa Saka, Wongani Mumba, Blessings Phakati, Lovemore Malunga, Peter Jere, Annie Chimaimba, Loviisa Mulanje, Samuel Mpinganjira, Mercy Josiah, Watipaso Mkhuta, Patricia Muwanya, Andrew Malanga, Henry Mwakalinga, Trasizio January, Dickson Hangiwa, Timothy Mutafya, Dan Msamanyada, Denis Chauma, Agatha Mlenga, Prince Goliati, Moses Msukuma, John Phalula. Without their hard and dedicated work over 2 months in 2016, this study would not have been possible. We also thank Elinor Barte, University of Bergen for important language editing of the text.

\section{References}

1. Butler EK, Tran TM, Nagarajan N, Canner J, Fuller AT, Kushner A, et al. Epidemiology of pediatric surgical needs in low-income countries. PloS One. 2017;12(3):e0170968.

2. Rose J, Weiser TG, Hider P, Wilson L, Gruen RL, Bickler SW. Estimated need for surgery worldwide based on prevalence of diseases: a modelling strategy for the WHO Global Health Estimate. Lancet Glob Health. 2015;3 Suppl 2:S13-20.

3. Bickler S, Rode H. Surgical services for children in developing countries. Bull World Health Organ. 2002;80:829-35.

4. Jha P, Chaloupka FJ, Moore J, Gajalakshmi V, Gupta PC, Peck R, et al. Disease control priorities in developing countries. Disease control priorities in developing countries. 2006.

5. Jamison DT, Breman JG, Measham AR, Alleyne G, Claeson M, Evans DB, et al., editors. Disease control priorities in developing countries. 2nd ed. The World Bank; 2006.

6. Bickler SW, Weiser TG, Kassebaum N, Higashi H, Chang DC, Barendregt JJ, et al. Global burden of surgical conditions. In: Debas HT, Donkor P, Gawande A, Jamison DT, Kruk ME, Mock CN, editors. Essential surgery: disease control priorities. 3rd ed. The World Bank; 2015. p. 19-40.

7. Sitkin NA, Farmer DL. Congenital anomalies in the context of global surgery. Semin Pediatr Surg. 2016;25(1):15-8.

8. Wright NJ, Anderson JE, Ozgediz D, Farmer DL, Banu T. Addressing paediatric surgical care on world birth defects day. Lancet. 2018;391(10125):1019.

9. Bickler SW, Sanno-Duanda B. Epidemiology of paediatric surgical admissions to a government referral hospital in the Gambia. Bull World Health Organ. 2000;78:1330-6.

10. Derbew M. Pediatric surgery in Eastern Africa: the unmet need. J Pediatr Surg. 2019;54(1):21-6.

11. Esquivel MM, Uribe-Leitz T, Makasa E, Lishimpi K, Mwaba P, Bowman K, et al. Mapping disparities in access to safe, timely, and essential surgical care in Zambia. JAMA Surg. 2016;151(11):1064-9.

12. Naomi Wright, Lukman Abdul-Rahman. Paediatric surgery across sub-Saharan Africa: a multi-centre prospective cohort study. Conference Paper: Global Paediatric Surgical Burden of disease.
PaedSurg Africa Research Collaboration. World Congress of Surgery, Basel, Switzerland, August 2017.

13. Ozgediz D, Poenaru D. The burden of pediatric surgical conditions in low and middle income countries: a call to action. J Pediatr Surg. 2012;47(12):2305-11.

14. Butler EK, Tran TM, Fuller AT, Brammell A, Vissoci JR, de Andrade L, et al. Quantifying the pediatric surgical need in Uganda: results of a nationwide cross-sectional, household survey. Pediatr Surg Int. 2016;32(11):1075-85.

15. Concepcion T, Mohamed M, Dahir S, Ismail EA, Poenaru D, Rice HE, et al. Prevalence of pediatric surgical conditions across Somaliland. JAMA Netw Open. 2019;2(1):e186857.

16. Varela C, Young S, Groen R, Banza L, Mkandawire NC, Viste A. Untreated surgical conditions in Malawi: A randomised cross-sectional nationwide household survey. Malawi Med J. 2017;29(3):231-6.

17. Kendig CE, Samuel JC, Varela C, Msiska N, Kiser MM, McLean SE, et al. Pediatric surgical care in Lilongwe, Malawi: outcomes and opportunities for improvement. J Trop Pediatr. 2014;60(5):352-7.

18. Lavy C, Tindall A, Steinlechner C, Mkandawire N, Chimangeni S. Surgery in Malawi-a national survey of activity in rural and urban hospitals. Ann R Coll Surg Engl. 2007;89(7):722-4.

19. Resolution W. 68.15. Strengthening emergency and essential surgical care and anaesthesia as a component of universal health coverage. May 2015. Geneva. World Health Assembly [cited 2018 Aug 1]. Available from: http://apps.who int/medicinedocs/documents/ s21904en/s21904en pdf.

20. Varela C, Young S, Mkandawire N, Groen RS, Banza L, Viste A. Transportation barriers to access health care for surgical conditions in Malawi a cross sectional nationwide household survey. BMC Public Health. 2019;19(1):264.

21. Varela C, Young S, Groen RS, Banza L, Mkandawire N, Moen $\mathrm{BE}$, et al. Deaths from surgical conditions in Malawi-a randomised cross-sectional nationwide household survey. BMC Public Health. 2020;20(1):1-8.

22. Demirguc-Kunt A, Klapper L, Singer D, Van Oudheusden P. The global findex database 2014: Measuring financial inclusion around the world. The World Bank; 2015.

23. Goverment M. Malawi: 2008 Population and housing census. Zomba: National Statistical Office. 2008.

24. Office NS. 2018 Malawi population and housing census. Preliminary report. National Statistical Office Zomba; 2018.

25. Groen RS, Samai M, Stewart K-A, Cassidy LD, Kamara TB, Yambasu SE, et al. Untreated surgical conditions in Sierra Leone: a cluster randomised, cross-sectional, countrywide survey. Lancet. 2012;380(9847):1082-7.

26. Henry JA, Windapo O, Kushner AL, Groen RS, Nwomeh BC. A survey of surgical capacity in rural southern Nigeria: opportunities for change. World J Surg. 2012;36(12):2811-8.

27. Maine RG, Linden AF, Riviello R, Kamanzi E, Mody GN, Ntakiyiruta G, et al. Prevalence of untreated surgical conditions in rural Rwanda: a population-based cross-sectional study in Burera District. JAMA Surg. 2017;152(12):e174013.

28. Burgos CM, Bolkan HA, Bash-Taqi D, Hagander L, Von Screeb J. The met needs for pediatric surgical conditions in Sierra Leone: estimating the gap. World J Surg. 2018;42(3):652-65.

29. Banza LN, Gallaher J, Dybvik E, Charles A, Hallan G, Gjertsen J-E, et al. The rise in road traffic injuries in Lilongwe, Malawi: A snapshot of the growing epidemic of trauma in low income countries. International J Surg Open. 2018;10:55-60.

30. Boubour A, Mboma S, Võ T, Birbeck GL, Seydel KB, Mallewa $\mathrm{M}$, et al. "We can't handle things we don't know about": perceived neurorehabilitation challenges for Malawian paediatric cerebral malaria https://dx.doi.org/10.4314/mmj.v33i2.2 
survivors. BMC Pediatr. 2020;20(1):1-16.

31. Neuman MJ, McConnell C, Kholowa F. From early childhood development policy to sustainability: the fragility of community-based childcare services in Malawi. Int J Early Child. 2014;46(1):81-99.
32. Kangaude GD. Adolescent sex and 'defilement' in Malawi law and society. Afr Hum Rights Law J. 2017;17(2):527-49. 